\title{
Congenital non-syndromal autosomal recessive deafness in Bengkala, an isolated Balinese village
}

Sunaryana Winata, I Nyoman Arhya, Sukarti Moeljopawiro, John T Hinnant, Yong Liang, Thomas B Friedman, James H Asher Jr

Department of Microscopic Anatomy, Faculty of Medicine, Udayana University, Denpasar, Bali, Indonesia

$S$ Winata

Department of Biochemistry, Faculty of Medicine, Udayana University, Denpasar,

Bali, Indonesia

I N Arhya

Laboratory of Biology, Faculty of Biology and the Inter University

Center for

Biotechnology, Gadjah

Mada University,

Yogyakarta, Indonesia

S Moeljopawiro

Department of

Anthropology,

Michigan State

University, East

Lansing, Michigan

48824, USA

J T Hinnant

Graduate Program in Genetics, Michigan State University, East

Lansing, Michigan

48824, USA

Y Liang

Graduate Program in Genetics, and Department of Zoology, 203 Natural

Science Building,

Michigan State

Michigan State

Lansing, Michigan

48824, USA

T B Friedman

$\mathrm{J} \mathrm{H}$ Asher Jr

Correspondence to:

Dr Asher.

Received 24 July 1994 Revised version accepted for publication 6 December 1994

\begin{abstract}
Bengkala is an Indonesian village located on the north shore of Bali that has existed for over 700 years. Currently, $2 \cdot 2 \%$ of the 2185 people in this village have profound congenital deafness. In response to the high incidence of deafness, the people of Bengkala have developed a village specific sign language which is used by many of the hearing and deaf people. Deafness in Bengkala is congenital, sensorineural, non-syndromal, and caused by a fully penetrant autosomal recessive mutation at the DFNB3 locus. The frequency of the DFNB3 mutation is estimated to be $9.4 \%$ among hearing people who have a $17 \cdot 2 \%$ chance of being heterozygous for DFNB3.
\end{abstract}

( $(\mathcal{F}$ Med Genet 1995;32:336-343)

A medical and genetic analysis of deafness in Bengkala, Bali began in 1990 with the identification of deaf subjects and their relationships. An anthropological investigation of Bengkala began in 1993 with studies of the cultural adaptations that were made in response to the high incidence of deafness in the village. Approximately $2 \cdot 2 \%$ of the inhabitants of this Balinese village are profoundly deaf.

We describe all of the families with congenital hereditary deafness in Bengkala, examine possible clinical features that might have been associated with the deafness, analyse the medical and village histories to determine the mode of inheritance, and describe a method of estimating the frequency of the deafness mutation in Bengkala given the high level of assortative mating among the deaf in this village. Our analyses presented here indicate that deafness in Bengkala is congenital, autosomal recessive, and non-syndromal.

\section{Materials and methods} STUDY POPULATION

In Bengkala, Bali, as with other Indonesian villages, officials maintain records of births, deaths, marriages, child development, the incidence of obvious common diseases, occupations, land ownership, and the number of fruit bearing trees. The records for Bengkala, as of June 1993, indicated that there were 2185 inhabitants. Historically, residents of Bengkala have exhibited a high incidence of goitre as is the case for many other villages in this part of Bali. ${ }^{1-3}$ Goitre has been the concern of Indonesian physicians for many years and has been the subject of extensive regional iodide therapy since $1980 .^{2}$ In addition to goitre, 47 of the residents of Bengkala are congenitally deaf. Fig 1 shows the families of all of the deaf people in Bengkala. It is suspected that the history of deafness in Bengkala spans many generations since virtually the entire population of Bengkala uses a village specific sign language as a means of integrating the deaf and hearing into a community.

\section{INFORMED CONSENT}

Subjects from Bengkala participated voluntarily in this research project and were either hearing or deaf. Permission to conduct this study was obtained from six Indonesian sources: (1) the Rector of Udayana University, Denpasar, Bali; (2) the Governor of Bali (Gubernur Kepala Daerah Tingkat1); (3) the regional director (Bupati) of the district containing Bengkala; (4) the subregional director (Camat); (5) the elected village head (Kepala desa) of Bengkala; and (6) each person participating in the project. The goals of the project and the possible risks of participating in the project were presented to each participant. This often required the use of a signing interpreter.

\section{FAMILY HISTORIES AND ASSESSMENT OF} DEAFNESS

Family histories and pedigrees were collected over a three year period and were used as a guide to interviews needed to obtain multiple independent confirmations of the hearing status, the time of onset of deafness, and the progression of hearing impairment for each deaf person. The people of Bengkala know that two hearing parents can produce children who are deaf at birth. Consequently, they have devised methods to test the hearing of young children. The first technique uses a loud noise to induce a startle response. Various objects are struck to produce a loud noise, including a gong from the Bengkala gamelan (orchestra). If a baby shows a startle response, it is assumed to be hearing while an absence of such a response indicates that the child is deaf. A second technique used by two deaf parents is to place their child with a hearing family for a short time in order to determine whether the child 
K1 I

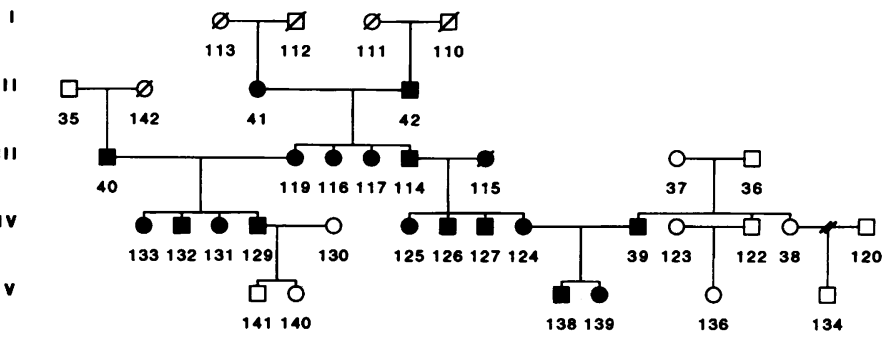

K11 ,

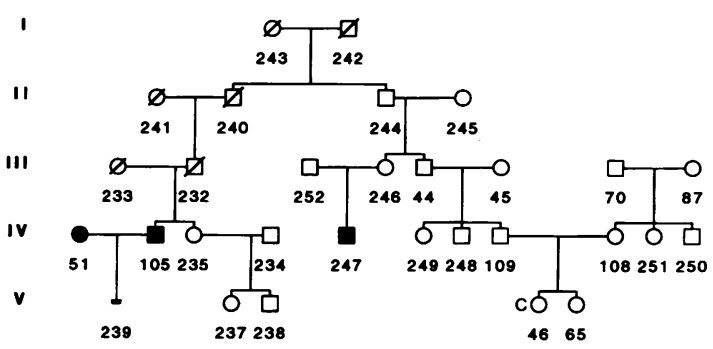

K2

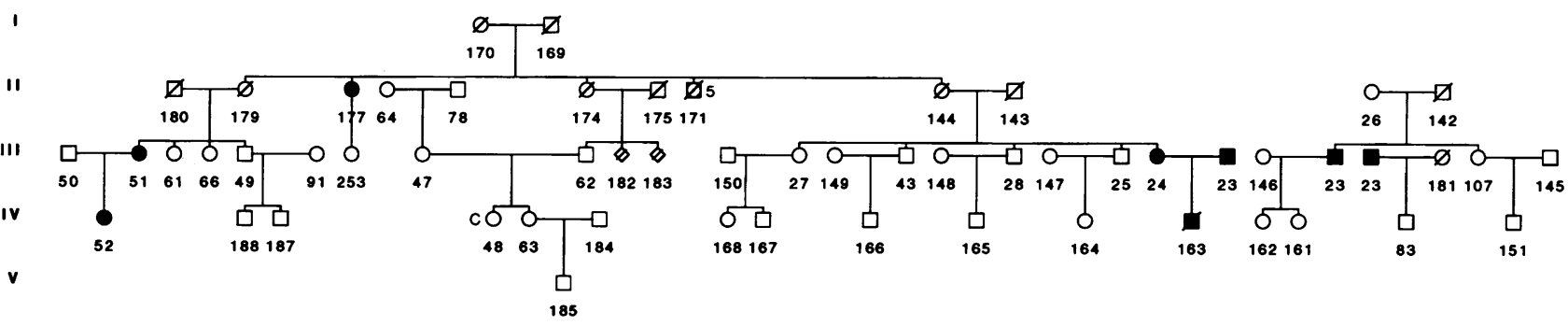

K3

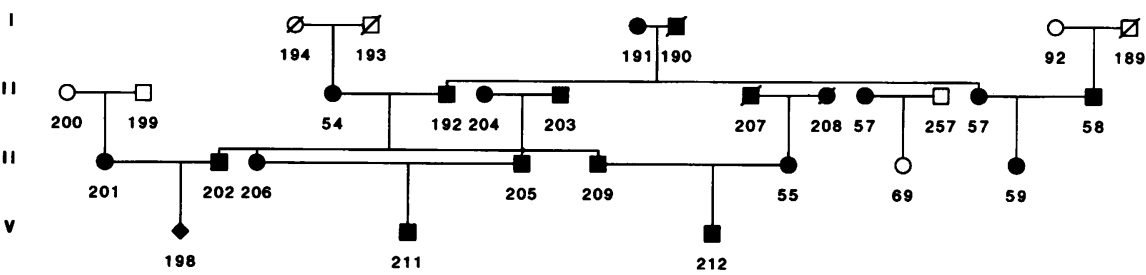

K4
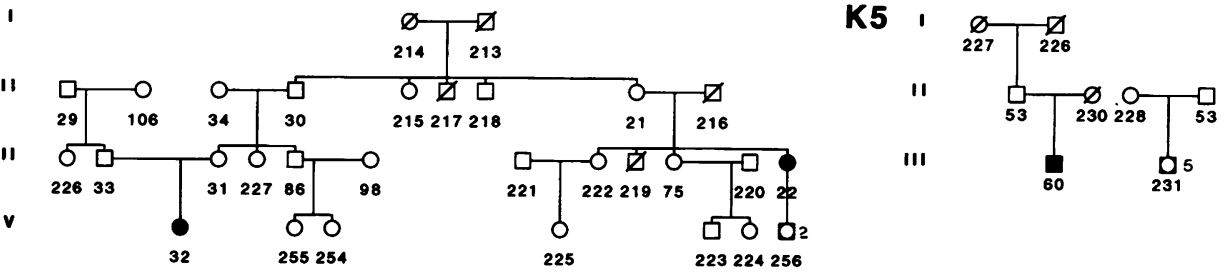

Figure 1 Six kindreds (K1,K2,K3,K4,K5, and K11) containing all of the deaf people found in Bengkala. Filled symbols indicate congenitally deaf subjects. Those who became deaf after birth are designated with a $C$ to the left of their symbol.

does or does not respond to the human voice. If the child is determined to be deaf, parents begin teaching the child the village sign language.
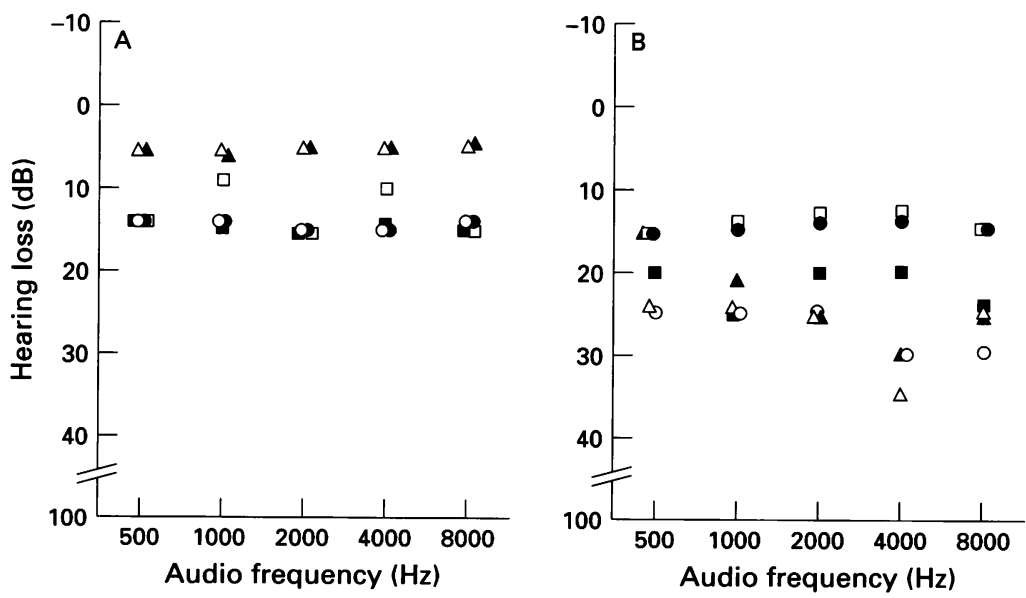

Figure 2 Audiograms for six obligate heterozygotes for the DFNB3 mutation. These are parents of deaf people in fig 1. (A) Obligate heterozygotes with normal hearing (K4-33

$\Delta, K 6-56 \square$, and K3-92 $\mathrm{O}$ ). (B) Obligate heterozygotes with borderline normal hearing $(K 1-36 \Delta, K 2-83 \square$, and $K 1-37 \bigcirc)$. Only subject 56 of $K 6$ is not represented in fig 1 since this kindred moved from Bengkala. Open symbols indicate left ears; filled symbols indicate right ears. The deaf persons from Bengkala (fig 1) were unresponsive when tested at the maximum sound pressure level of $90 \mathrm{~dB}$ at the frequencies indicated.
In order to determine the clinical nature of the deafness observed in Bengkala, audiological examinations were conducted initially in 1990 using a vibrating $\mathrm{F} 512 \mathrm{~Hz}$ tuning fork placed next to the ear and then on the mastoid bone for a quick qualitative survey of the presumed hearing and deaf subjects in Bengkala. Presumed normal hearing, obligate hearing DFNB3 heterozygotes, and deaf people were then given audiological examinations in a quiet room in Bengkala with a type $\mathrm{D}$ audiometer from Minaty Medical Science Co Ltd, Osaka, Japan. Audiograms were obtained for 24 deaf people ( 11 males and 13 females) and 14 hearing people (eight males and six females) known to be a parent of a deaf child (figs 1 and 2). The maximum sound pressure level used to establish non-responsiveness of the deaf people was $90 \mathrm{~dB}$ at 500,1000,2000,4000, and $8000 \mathrm{~Hz}$. The Romberg and tandem walk tests of 44 deaf people were performed to evaluate vestibular disturbances.

POPULATION SAMPLING

In the summer of 1992 , blood samples from 21 hearing and deaf villagers from Bengkala were obtained and DNA was extracted. These 
21 samples were typed for four linked dinucleotide repeat marker loci (STRs), D19S179 (Mfd176), D19S253 (Mfd239), D19S47 (Mfd9), and D19S200 (MS265), known to be highly informative in populations of western European ancestry. ${ }^{4}$ From an analysis of these four STR markers in the 21 hearing and deaf people, the inhabitants of Bengkala appeared to have levels of genetic variability similar to the levels found in western populations indicating that STRs would be useful in determining the map position of DFNB3. ${ }^{5}$

In the summer of 1993,109 additional villagers were interviewed, gave their consent to participate, were photographed, and subsequently gave blood samples for DNA extraction. These villagers included 51 hearing men and women who professed to have no known first or second degree deaf relatives. Of these 51 volunteers, DNA samples from 48 Representative Bengkala Individuals (RBIs) were used to determine marker allele frequencies in the village of Bengkala. The genealogies of the RBIs were also investigated in the summer of 1993. Each RBI was asked to look at the photographs taken when blood samples were drawn to determine if any were kinsmen or affines of each other or of the deaf people in our sample. Queries were also made to determine if any additional deaf people existed in the village that were unknown to us. This process uncovered subject 177, K2 (fig 1), a very elderly deaf woman, who was ill at the time and shielded from visitors. Subject 177 had eight hearing sibs, two of whom (179 and 144) were carriers of the recessive deafness mutation. Deaf villagers were also interviewed with the aid of a hearing interpreter who knew the Bengkala sign language, generally in a setting where hearing members of the deaf people's families were present. They were also asked to look at the pictures of RBIs to identify possible kinsmen. These queries uncovered a few links between members of small families containing deaf people allowing us to group all the deaf in Bengkala into the six kindreds $(\mathrm{K} 1$, $\mathrm{K} 2, \mathrm{~K} 3, \mathrm{~K} 4, \mathrm{~K} 5$, and $\mathrm{K} 11$ ) as shown in fig 1 .

To ensure the correct identity of each person, Polaroid photographs were made and attached to an identity card that accompanied the person as an Indonesian phlebotomist, in the presence of one of the authors, withdrew two $10 \mathrm{ml}$ sodium heparinised blood samples. Two additional physicians from the local community clinic (Puskusmas) near Bengkala were also present at the time blood samples were drawn and examined each participant as well as any other person in Bengkala wishing medical advice. DNA was extracted using the Super QuikGene DNA isolation kit (Analytical Genetic Testing Center Inc, Denver, Colorado). DNA samples were used initially to check paternity of one critically important person (No 69, K3, fig 1), the only hearing person presumably with two deaf parents, and then to map the deafness gene segregating in Bengkala (DFNB3). ${ }^{6}$
ANTHROPOLOGICAL INVESTIGATIONS

Between 1990 and 1993, 13 pedigrees of the deaf and their relatives had been identified. The initial anthropological investigations conducted in the summer of 1993 were aimed at collecting additional information on kinship and marriage in Bengkala and obtaining a better understanding of the history of Bengkala.

The process of learning the social organisation and ritual life of the community was then begun through interviews and observation. Historical studies were initiated to uncover records pertaining to the dates when Bengkala might have experienced population bottlenecks and when congenital deafness might first have become apparent in Bengkala. The historical study of Bengkala involved collecting personal histories and traditional village origin stories as well as examining the village archives held by the Gedong Kertia Library in Singaraja. Prasasti, metal plates written in Sanskrit in the 12th century, were examined and found to describe the village charter granted to Bengkala by the King of Bali.

\section{ANALYSIS OF HISTORICAL RECOMBINANTS}

Using 150 STRs located an average of $30 \mathrm{cM}$ apart, DFNB3 was found to be linked to the pericentromeric region of chromosome $17 .{ }^{6}$ A conventional linkage analysis involving 250 CEPH family members ${ }^{6}$ was then used to construct a linkage map of 13 chromosome 17 STRs that flank DFNB3. Using historical recombinant haplotypes of these 13 DFNB3 flanking marker loci on $17 \mathrm{p}$ among 13 deaf people from Bengkala, the known recombination fractions from the CEPH families and equation 1 below, the number of generations since the appearance of the DFNB3 gene in Bengkala was estimated to be:

$$
\mathrm{g}=-[\ln (1-\mathrm{HR})] / \theta
$$

where $\theta$ is the known frequency of recombination between two linked markers, HR is the proportion of historical recombinant haplotypes observed for these markers, and $\mathrm{g}$ is the number of generations assumed to have passed since DFNB3 appeared in Bengkala. ${ }^{78}$ This analysis assumes that the DFNB3 mutation first appeared in Bengkala in complete allelic disequilibrium with closely linked markers. Over time, as a consequence of recombination and possibly mutation of linked marker alleles, the DFNB3 mutation has become associated with different combinations of closely linked marker alleles, that is, different recombinant haplotypes.

The number of generations since DFNB3 appeared in Bengkala was also estimated using a different method of calculating the proportion of disequilibrium that is expected to remain since the mutation entered the population given by equation 2 :

$$
g=\frac{\ln \left[\left((r / n)-p_{1}^{2}\right) /\left(1-p_{1}^{2}\right)\right]}{\ln (1-\theta)}
$$


where $r$ is the observed number of homozygous recessive deaf people who are also homozygous for the $\mathrm{i}^{\text {th }}$ linked marker allele following $\mathrm{g}$ generations of linkage disequilibrium decay, $p_{i}$ is the frequency of the linked $i^{\text {th }}$ marker allele, $p_{i}^{2} n$ is the expected number of deaf also homozygous for the $i^{\text {th }}$ marker allele provided Hardy-Weinberg and allelic equilibrium has been reached, and $n$ is the number of homozygous recessive deaf people examined.

\section{Results}

BIOLOGICAL NATURE OF DEAFNESS

Bengkala has a long history of reported goitre. ${ }^{1}$ Since 1980, the people in Bengkala have participated in an extensive iodide supplementation programme to eliminate goitre from Bali. Deafness in Bengkala was initially suspected to be caused by Pendred syndrome (MIM 274600) ${ }^{10}$ which is inherited as an autosomal recessive trait in which subjects are deaf with goitre. $\chi^{2}$ analysis indicates that sex, goitre, and hearing status are randomly associated among members of the kindreds presented in fig $1\left(\chi^{2}=2 \cdot 87,3 \mathrm{df}, \mathrm{p}=0.412\right)$. Regardless of hearing status, sex and goitre are randomly associated among members of the kindreds shown in fig 1 and the RBIs $\left(\chi^{2}=\right.$ $4 \cdot 30,3 \mathrm{df}, \mathrm{p}=0 \cdot 231)$. These observations rule out the possibility that deafness in Bengkala is caused by Pendred syndrome. However, there is presently an unexplained association between sex and goitre in Bengkala with women exhibiting a higher incidence of goitre than men $\left(\chi^{2}=10 \cdot 95,1 \mathrm{df}, \mathrm{p}=0.000941\right)$.

There are over 35 additional syndromes which have deafness as one of the reported findings. ${ }^{11-14}$ For example, subjects with syndromes exhibiting hearing impairments may also show facial dysmorphic features, for example, Waardenburg syndrome with dystopia canthorum $^{15}$ and Noonan syndrome with hypertelorism. ${ }^{12}$ Facial measurements of inner canthal distance, inner pupillary distance, and outer canthal distance of the RBIs do not differ significantly from measurements of deaf subjects (data not shown). Thus, deaf people do not exhibit facial dysmorphic features associated with Waardenburg syndrome type 1 . To the best of our knowledge, all deaf members of Bengkala are without any additional stigmata. Deafness in Bengkala appears to be nonsyndromal.

\section{HEARING TESTS}

Audiological examinations indicated that deafness in Bengkala is bilateral, sensorineural, and that 24 tested deaf people were uniformly nonresponsive to pure tone audiological examinations at sound pressure levels up to $90 \mathrm{~dB}$. Histories of each deaf person in Bengkala indicate that hearing loss was congenital in all but two profoundly deaf subjects (Nos 46 and 48 , designated $C$ in fig 1). These latter two subjects were excluded from the segregation and population analyses given below and the mapping analyses. ${ }^{6}$ Physical examinations of 44 deaf people failed to show any obvious neurological anomalies including vestibular disturbances that would be indicated by the tandem Romberg test.

Fourteen people known to have parented a deaf child and who are thus obligate heterozygotes were examined and their representative pure tone audiograms appear in fig 2. Seven of these obligate heterozygotes represented by fig $2 \mathrm{~A}$ produced normal pure tone audiograms while the remaining seven of these heterozygotes represented by fig $2 \mathrm{~B}$ produced borderline normal pure tone audiograms. People were considered borderline normal if they exhibited a $25 \mathrm{db}$ deficit at a minimum of two frequencies from $500 \mathrm{~Hz}$ to $8000 \mathrm{~Hz}$. A more complete survey of the population of Bengkala is needed before we may conclude that a high proportion of DFNB3 heterozygotes have a borderline hearing impairment.

PEDIGREES AND THE SEGREGATION ANALYSIS All familial relationships shared by deaf people in Bengkala are indicated by the pedigrees presented in fig 1 . In families studied to date (fig 1), no indications of consanguineous marriages have been discovered. Examination of the kindreds in fig 1 indicates that there are 21 deaf men and 26 deaf women living in Bengkala. This observation suggests that deafness in Bengkala is not a sex linked or sex influenced trait. In addition, 14 marriages involving two unrelated deaf parents produced 15 deaf and one hearing (No 69) offspring (fig 1). The presence of 15 deaf offspring from apparently unrelated parents who are both deaf strongly supports the conclusion that deafness in Bengkala is caused by a fully penetrant autosomal recessive mutation at a single locus, DFNB3. The single exceptional subject (fig 1, No 69) was evaluated using 13 STR markers on chromosomes $2,4,7,17$, and 19 . For six of these 13 marker loci (D4S194 (Mfd146), D7S559 (Mfd265), D17S799 (AFM192yh2), GATA10H07, D17S261 (Mfd41), and D17S520 (Mfd15A) subject No 69 possesses alleles not present in the father of record (No 58). New STR alleles may arise with a mutation rate as high as $10^{-3} \cdot{ }^{16}$ The probability that all six nonmaternal alleles found in subject No 69 arose by mutation is at most $10^{-18}$, a highly unlikely event. To date, children born to two deaf parents in Bengkala are always congenitally deaf.

A total of 16 deaf people in Bengkala were born to parents who are both hearing (fig 1). If deafness in Bengkala is caused by a fully penetrant autosomal recessive mutation at a single locus, the marriages producing these 16 people must involve parents who are heterozygous for a mutation at this locus. Such marriages should produce one deaf child for every three hearing children. In Bengkala, we observed 16 deaf to 18 hearing children, a significant deviation from an expected mendelian $1: 3$ ratio $\left(\chi^{2}=8.824,1 \mathrm{df}, \mathrm{p}=\right.$ $0.002984)$. Such a deviation, however, is consistent with complete truncate ascertainment bias which is caused by an apparent deficiency in the number of hearing children from het- 
Table 1 Marriages and the expected frequencies of deaf children from these marriages assuming random marriages among hearing parents in Bengkala

\begin{tabular}{llll}
\hline$F \quad M \quad$ Frequency of marriage & Deaf progeny \\
$+I++I+\frac{\mathrm{P}}{(2-\mathrm{P})} \times \frac{\mathrm{P}}{(2-\mathrm{P})} \times 0=0$ \\
$+I-+I+\frac{2(1-\mathrm{P})}{(2-\mathrm{p})} \times \frac{\mathrm{P}}{(2-\mathrm{P})} \times 0=0$ \\
$+I++I-\frac{\mathrm{P}}{(2-\mathrm{p})} \times \frac{2(1-\mathrm{P})}{(2-\mathrm{P})} \times 0=0$ \\
$+/-+I-\frac{2(1-\mathrm{P})}{(2-\mathrm{p})} \times \frac{2(1-\mathrm{P})}{(2-\mathrm{P})} \times 1 / 4=\frac{(1-\mathrm{P})^{2}}{(2-\mathrm{P})^{2}}$
\end{tabular}

$\mathrm{F}=$ father; $\mathrm{M}=$ mother; $+=$ normal allele and $-=$ the mutated DFNB3 allele; relative frequencies derived from equation 4 The mutation $(-)$ segregating in these families is assumed to be fully penetrant.

erozygous parents who, by chance, produce no deaf children and are, therefore, not ascertained. Correcting for ascertainment bias, we expected 19.6 (SD 2.0) deaf offspring. ${ }^{17}$ Since the expected (19.6) and observed (16) deaf progeny are not significantly different at $p=0 \cdot 05$, we cannot reject the underlying hypothesis that deafness in Bengkala is caused by a fully penetrant autosomal recessive mutation at a single locus. As this mutation causes nonsyndromal autosomal recessive deafness, it has been designated by Dr P McAlpine as DFNB3 in accord with the HUGO Nomenclature Committee. ${ }^{6}$

POPULATION GENETICS

By a conventional Hardy-Weinberg analysis, the frequency of the mutant DFNB3 allele in Bengkala is $0 \cdot 147(14.7 \% \mathrm{HW})$ and the frequency of hearing adults heterozygous for the DFNB3 mutation is $0.252(25 \cdot 2 \% \mathrm{HW})$. These calculations assume random marriages among all members of the village. As the fre- quency of the deaf in Bengkala is $2 \cdot 2 \%$, if marriages are random with respect to hearing status, we would expect to find no more than one marriage between deaf partners $\left(0 \cdot 022^{2} \times 2185 / 2=0 \cdot 529\right)$. At present, there are 14 couples in Bengkala in which both members are deaf. Hence, marriages in this community are not random with respect to the hearing status of a person. Deaf people in Bengkala tend to marry other deaf people and have all deaf progeny (fig 1). Therefore, a standard Hardy-Weinberg analysis provides an overestimate of the frequency of the DFNB3 allele in Bengkala.

An alternate method to estimate the frequency of the DFNB3 allele among hearing subjects can be obtained by considering only hearing adults and their progeny. For the sake of this analysis, we assume that there is random marriage among hearing people in Bengkala. In this case:

$$
\begin{aligned}
& \mathrm{P}^{2}(+/+ \text { hearing }) \\
& \quad+2 \mathrm{P}(1-\mathrm{P})(+/- \text { hearing })=\mathrm{P}(2-\mathrm{P})
\end{aligned}
$$

where $(1-P)$ indicates the frequency of the DFNB3 mutation and $+/-$ indicates subjects carrying the DFNB3 mutation. The normalised proportions of the above frequencies are given by:

$$
\mathrm{P} /(2-\mathrm{P})(+/+)+2(1-\mathrm{P}) /(2-\mathrm{P})(+/-)=1
$$

Table 1 shows the types of marriages, their expected frequencies, and the expected population frequency of deaf progeny from these marriages occurring in Bengkala derived from equation 4. Using the total frequency of deaf people born to parents who are both hearing $[16 /(2,185-47+16)=0 \cdot 0074]$, the frequency of the DFNB3 mutation among hearing people in Bengkala, $1-\mathrm{P}=0.094$ or $9 \cdot 4 \%(14 \cdot 7 \% \mathrm{HW})$ while the frequency of hearing adults who ac-

Table 2 The marker loci surrounding DFNB3, the number of deaf people homozygous for a specific marker allele ( $r$ ), the frequency of this allele $\left(p_{i}\right)$, the distance between markers in centimorgans $(c M)$ associated with the recombination fraction $(\theta)$, the number of recombinants among $250 \mathrm{CEPH}$ family members (CEPH Rec), historical recombinants

\begin{tabular}{|c|c|c|c|c|c|c|c|c|c|c|}
\hline Marker & Locus & $r$ & $p_{i}$ & $c M$ & $\theta$ & $C E P H \operatorname{Rec}$ & $H R$ & $g_{1}$ & $g_{2}$ & $M b$ \\
\hline Mfd144 & D17S520 & 5 & $0 \cdot 227$ & $0 \cdot 0$ & 0.000 & 0 & 9 & - & - & - \\
\hline AFM225zc1 & D17S804 & 7 & $0 \cdot 215$ & $5 \cdot 4$ & 0.054 & 14 & 9 & $7 \cdot 9$ & $9 \cdot 1$ & - \\
\hline GATA10HO7 & & 6 & $0 \cdot 227$ & $4 \cdot 1$ & 0.041 & 10 & 4 & $4 \cdot 1$ & $7 \cdot 3$ & - \\
\hline AFM192yh2 & D17S799 & 8 & $0 \cdot 283$ & $12 \cdot 9$ & $0 \cdot 126$ & 32 & 6 & $2 \cdot 1$ & $3 \cdot 3$ & $1 \cdot 2$ \\
\hline VAW409 & D17S122 & 12 & 0.533 & 0.0 & 0.000 & 0 & 1 & $39 \cdot 2$ & 113.6 & 0.1 \\
\hline Mfd41 & D17S261 & 13 & 0.511 & $3 \cdot 2$ & 0.032 & 8 & 0 & - & - & $4 \cdot 0$ \\
\hline AFM234tal & D17S805 & 13 & 0.475 & $2 \cdot 1$ & 0.021 & 5 & 2 & $3 \cdot 8$ & $9 \cdot 8$ & - \\
\hline AFM026vh7 & D17S783 & 11 & 0.423 & $1 \cdot 7$ & $0 \cdot 017$ & 4 & 1 & $2 \cdot 3$ & $12 \cdot 2$ & - \\
\hline GATA2CO7 & & 10 & $0 \cdot 720$ & $3 \cdot 6$ & 0.036 & 9 & 2 & $2 \cdot 2$ & $4 \cdot 8$ & - \\
\hline AFM179xg11 & D17S798 & 10 & 0.614 & $3 \cdot 5$ & 0.035 & 9 & 4 & $4 \cdot 8$ & $10 \cdot 1$ & - \\
\hline GGAA7D11 & & 7 & 0.076 & $4 \cdot 5$ & 0.045 & 11 & 6 & $5 \cdot 8$ & $6 \cdot 3$ & - \\
\hline $\begin{array}{l}\text { Mfd15 } \\
\text { AFM200zf4 }\end{array}$ & $\begin{array}{l}\text { D17S250 } \\
\text { D17S800 }\end{array}$ & $\begin{array}{l}8 \\
6\end{array}$ & $\begin{array}{l}0.308 \\
0.570\end{array}$ & $2 \cdot 6$ & 0.026 & 6 & 3 & $4 \cdot 7$ & $17 \cdot 6$ & - \\
\hline
\end{tabular}
(HR) observed among the 13 deaf, estimated number of generations $\left(g_{i}\right)$ since DFNB3 was introduced into Bengkala calculated from equations 1 and 2 , and the distance between markers in megabases of DNA (Mb)

Allele frequencies $\left(p_{i}\right)$ estimated from 48 RBIs. 
tually carry the DFNB3 mutation is 0.172 or $17 \cdot 2 \%(25 \cdot 1 \% \mathrm{HW})$. This second estimate of the frequency of DFNB3 in Bengkala may also be an overestimate.

Bali contains seven paseks, title groups or supravillage connections based on an ancient migration, or wave of conquest, from one of the Hindu palace-temple complexes established following the Hindu conquest of Bali during the 12th century. Many of the deaf in Bengkala are members of pasek Gelgel. This would suggest that marriages even among the hearing in Bengkala may not be random. However, as the complete pattern of marriages in Bengkala has yet to be determned and as a direct method for identifying the presence of the DFNB3 mutation requires that DFNB3 be cloned, it is not possible at this time to obtain an unbiased estimate of the frequency of the DFNB3 mutation in Bengkala.

\section{WHEN WAS DFNB3 INTRODUCED INTO} BENGKALA?

DFNB3 has been mapped to the pericentromeric region of chromosome 17 using a new genome wide disequilibrium search, a strategy described briefly elsewhere ${ }^{6}$ and in detail in a manuscript in preparation (Asher $e t$ $a l$ ). The current map distances between markers in the region to which DFNB3 maps are presented in the column of table 2 labelled cM. The STRs D17S122 (VAW409) and D17S783 (AFM026vh7) flank DFNB3 and are $5.3 \mathrm{cM}$ apart. ${ }^{6}$ If double recombinants are minimised, these two markers are separated by three historical recombinations. Given the haplotypes present in the 13 deaf subjects (table 2), DFNB3 appears to be in complete allelic disequilibrium with respect to the STRs D17S261 (Mfd41) and D17S805 (AFM234ta1). As indicated by equation $1,{ }^{7}$ the decay of this disequilibrium is dependent upon the distance between markers as a recombination fraction $(\theta)$ and the number of generations $(\mathrm{g}$ ) since DFNB3 appeared in the population. The more distant the marker is from the DFNB3 mutation, the larger number of historical recombinant (HR) haplotypes will be expected and observed (table 2). The frequency of these recombinant haplotypes and equation 1 were used to estimate the number of generations since DFNB3 appeared in Bengkala. As an example of this calculation, consider the markers D17S805 and D17S783 that are $2 \cdot 1 \mathrm{cM}$ apart. In this interval, we observed $\mathrm{HR}=2 / 26$ historical recombinant haplotypes, $\theta=0.021$ recombination fraction independently determined from CEPH families, and the calculated number of generations since DFNB3 appeared is $g=-[\ln (1-2 / 26)] /$ $0 \cdot 021=3 \cdot 8$. Considering all marker intervals and the associated recombinant haplotypes, table 2 presents 10 estimates for the number of generations since DFNB3 first appeared in Bengkala. In general, these values range between $2 \cdot 2$ and 7.9 generations with a single exception.

From a conventional linkage analysis, D17S122 and D17S261 exhibited no re- combinants out of $250 \mathrm{CEPH}$ family members. ${ }^{6}$ These two loci are approximately $100 \mathrm{~kb}$ apart $^{618}$ which is roughly equivalent to $\theta=$ $0 \cdot 001 .{ }^{19}$ Among the 13 deaf, there is a single recombinant haplotype for these two markers. Using this marker combination and equation 1, DFNB3 may have been introduced into Bengkala approximately $39 \cdot 2$ generations ago. As a generation in Bengkala can be as short as 15 years, the generation estimates from table 2 indicate that DFNB3 may have appeared in Bengkala as recently as 32 years ago or as long ago as 566 years.

The number of generations since the DFNB3 mutation was introduced into Bengkala (g) was also estimated from equation 2 which uses the frequency of the linked marker allele. For the markers D17S805 and D17S783, $g=9.8$ generations when $r / n=11 / 13, \theta=0.021$, and $p_{i}=$ 0.423 (which is assumed not to have changed since the introduction of the DFNB3 mutation into Bengkala). The values of $g$ estimated from equation 2 are also presented in table 2 . Thus, we have two sets of estimates of the number of generations since DFNB3 appeared in Bengkala. Including all 10 estimates, equation 1 yields estimates of $\mathrm{g}=7 \cdot 7$ (SD 11.2) generations while equation 2 yields estimates of $\mathrm{g}=19 \cdot 4$ (SD 33.3) generations. These two estimates are not significantly different because of the large variation found in each estimate and suggest that on average DFNB3 may have appeared in Bengkala between 10 and 20 generations or 150 to 300 years ago.

\section{Discussion}

Human childhood deafness occurs worldwide with an incidence of $1: 650$ to $1: 2000$ live births. ${ }^{2021}$ At least $50 \%$ of congenital deafness is thought to be hereditary. ${ }^{22}$ Seventy-five percent of hereditary congenital deafness is the result of autosomal recessive mutations. ${ }^{2123-25}$ Many people with autosomal recessive deafness show no other obvious associated features and so would be classified as having non-syndromal deafness. The total number of unlinked mutant loci producing non-syndromal autosomal recessive deafness has been estimated to be between 20 and 2000, based on surveys of interethnic marriages in which the majority of marriages involving two unrelated deaf parents produce all hearing offspring. ${ }^{21}$ In contrast, two deaf parents in Bengkala always produce deaf children (fig 1).

Recently, Friedman et $a l^{6}$ mapped the DFNB3 mutation segregating in Bengkala using a new strategy, allele frequency dependent homozygosity mapping (AHM). ${ }^{9}$ AHM relies on the existence of a dense genetic map of highly polymorphic genetic markers, assumes that the population examined is polymorphic for these markers, and uses the fact that all mutations arise in allelic disequilibrium with linked markers. To apply AHM, a reliable determination of highly polymorphic marker allele frequencies must be made. ${ }^{9}$ This required the availability of unaffected, unrelated, Representative Bengkala Individuals (RBIs). In 
the case of DFNB3, an examination of 13 deaf people and 48 RBIs provided sufficient information to map DFNB3 to the pericentromeric region of chromosome $17 .{ }^{69}$

Historical recombinant haplotypes (table 2) used to narrow the chromosomal location of DFNB3 can also be used along with linkage data from CEPH families ${ }^{6}$ and equation 1 and 2 to estimate the number of generations since DFNB3 was introduced into Bengkala. Our estimates using equation 1 range from $2 \cdot 1$ generations to a maximum of $39 \cdot 2$ generations ago while the estimates from equation 2 range from 3.2 to 113.6 generations ago. For both sets of estimates, there is a single major outlier involving the same genetic region, D17S261 to D17S122, which shows no meiotic recombinants among $250 \mathrm{CEPH}$ family members. In the absence of this outlier, the average estimate using equations 1 and 2 respectively are $4.2(\mathrm{SD} 1.9)$ and $8.9(\mathrm{SD} 4.3)$ generations or $63.0(\mathrm{SD} 28.5)$ and $133.5(\mathrm{SD} 64.5)$ years for a 15 year generation.

In order to obtain an independent estimate of the date when DFNB3 first appeared in Bengkala, investigation of deafness in other Balinese villages were begun. Villages within 2 kilometres of Bengkala, Tamblang ( 4 deaf $/ 4127$ inhabitants), Bila (7/2097), and Kubutambahan $(5 / 8947)$ all have low frequencies of deafness compared to Bengkala (49/2185). On the other hand, Anturan, a small village approximately $30 \mathrm{~km}$ from Bengkala has nine subjects with non-syndromal deafness (approximately $1 \%$ of the population). There appears to be an historical relationship between deafness in Bengkala and in Anturan. Many of the deaf in Bengkala and all of the deaf in Anturan are members of pasek Gelgel. The origin temple (kawitan) serves as the ultimate reference point for all members of a pasek, who periodically return to the temple for ceremonies. Members of each pasek remember the moves their ancestors made as they spread out across Bali from a kawitan, and periodically perform ceremonies at the temples of the various villages where their ancestors once lived. Because of migration of the various pasek during the conquest of Bali, it is possible that the same mutation for congenital recessive deafness is segregating in Bengkala and Anturan and that the high frequency of the gene in these two villages is a consequence of a reproductive bottleneck or founder effect that occurred sometime after the 12th century when the Hindu conquest and migrations began but before the time members of pasek Gelgel moved to Anturan and Bengkala. Our genetic estimates suggest that this bottleneck could have occurred within the last 200 years, nearly 600 years after the Hindu conquest and migration.

The two procedures for estimating the time since DFNB3 first appeared in Bengkala give averages of 63 and 134 years. If correct, the people of Bengkala recognised the existence of a genetic problem, developed social customs to identify newborn deaf children, developed a sign language that is taught to deaf and hearing children alike, and integrated the deaf into the community in slightly less than 150 years.
These ages appear consistent with the pedigrees in fig 1 that indicate the presence of deaf people and a relatively high frequency of the DFNB3 mutation at least four generations (60 years) ago.

The portion of chromosome 17 presented in table 2 has 12 linkage intervals with an average genetic distance from $\mathrm{CEPH}$ meiotic recombinations of $3.6 \mathrm{cM}$ and an average of 3.9 historical recombinants per interval. In the interval between D17S261 and D17S805, the interval suspected to contain DFNB3, 250 CEPH family members exhibited eight meiotic recombinations for a value of $\theta=0.032$ $(3.2 \mathrm{cM})$. This region, however, did not exhibit a single historical recombinant among the 13 deaf people. A contingency $\chi^{2}$ analysis comparing meiotic and historical recombinations indicates a significant difference between these two sources of recombination $\left(\chi^{2}=32 \cdot 32,11 \mathrm{df}\right.$ at $\mathrm{p}=0 \cdot 00066)$. The major contributions to this $\chi^{2}$ come from the region between D17S520 and D17S840 which is over $20 \mathrm{cM}$ away from the interval suspected to contain DFNB3. Eliminating this region from consideration, the contingency $\chi^{2}$ is not significant $\left(\chi^{2}=11.45\right.$, $10 \mathrm{df}$, at $\mathrm{p}=0.323341$ ). This suggests that meiotic recombinants and historical recombinants, with the exception of a single map interval, are consistent with each other, lending support to the results obtained from our analysis of the historical recombinants.

Of the mutations causing deafness, those that cause non-syndromal autosomal recessive deafness are probably the most challenging to map because of the large number of genes causing this type of deafness and the difficulty of finding large consanguineous families. The first two, NSRD1 and NSRD2 (now designated DFNB1 and DFNB2, respectively, by the HUGO Nomenclature Committee), were mapped to chromosomes 13 and 11 using conventional linkage analyses of extended, consanguineous pedigrees. ${ }^{2627}$ The DFNB1 mutation has variable expressivity and the DFNB2 mutation has a variable age of onset and possibly incomplete penetrance. From data presented here, the recessive deafness mutation segregating in Bengkala differs phenotypically from DFNB1 and DFNB2 in that DFNB3 is a fully penetrant recessive mutation that causes profound congenital deafness and maps to chromosome $17 \mathrm{p} .^{6}$

In summary, Bengkala is a Balinese village that is at least 700 years old with approximately 2185 inhabitants, $2 \cdot 2 \%$ of whom are deaf. A complete survey of all of the villagers identified six kindreds with 49 deaf people. Physical and audiological examinations and family histories indicate that DFNB3 is congenital, sensorineural, and non-syndromal. A segregation analysis presented here indicated that deafness is caused by a fully penetrant autosomal recessive mutation of the DFNB3 gene. A population analysis indicates that $17 \cdot 2 \%$ of hearing people in Bengkala are heterozygous for the mutated DFNB3 gene. Using mapping data published elsewhere,${ }^{6}$ historical recombinants between STRs closely linked to DFNB3 indicate that the DFNB3 mutation could have 
arisen or arrived in Bengkala by a stochastic event within the last 200 years.

We are grateful for the help and hospitality of the community of Bengkala. We thank the late Dr Soedarminto, Project Director and Chairman, Department of Biochemistry, Faculty of Medicine, Udayana University, for his support and guidance of this project. We also thank Dr Joedoro Soedarsono, Director, IUC for Biotechnology, Gadiah Mada University, Yogyakarta, for suppoting this research project in its infancy and the use of supporting this research project in its infancy and the use of DNA extractions and PCR amplifications. We thank M Swinda, DNA extractions and PCR amplifications. We thank M Swinda, phlebotomist, and Dr Sudewa Djelantik, Director, Red Cross Blood Bank, Sangla Bali Hospital, for the use of his laboratory to extract genomic DNA. We thank Dr W Sudana, Department of Otolaryngology, Dr Dwi Sutanegara, Department of Internal Medicine, Dr W Kondra, Department of Neurology, and Dr Darmasutapa, Department of Psychology, Udayana University, for their evaluations of hearing and deaf people from Bengkala. We thank the previous and present Kepala Desa of Bengkala, and Dr Wayan Artama, IUC for Biotechnology, Gadjah Mada University, Yogyakarta for their assistance in conducting this research. YL was supported jointly by the Michigan State University Graduate Program in Genetics and from a grant to JHA and TBF from NIDCD (R01 DC01160-02). We acknowledge the Deafness Research Foundation for support of this project. Personal funds of SW,
supported the majority of this project.

1 Noosten HH. Krop op Bali: Overgedrukt uit het geneeskundig tijdschrift voor Nederlandsch. Indie Apt 1934;16: kundig tijdsc

2 Soedarminto, Sutanegara D, Arhya W, et al. Research on endemic goiter in Bali: a cooperative study between the Regional endemic goiter in Bali: a cooperative study between the Regional Development Unit in Bali and Udayana Universig

3 Report from a joint WHO/UNICEF/ICCIDD Consultation. Indications for assessing iodine deficiency disorders and Indications for assessing iodine defT 1993;1:14.

4 Weber JL, Wang $\mathrm{Z}$, Hansen $\mathrm{K}$, et al. Evidence for human meiotic recombination interference obtained through construction of a short tandem repeat polymorphism linkage map of chromosome 19. Am f Hum Genet 1993;53:107995.

5 Morell R, Liang Y, Asher JH Jr, et al. Analysis of short tandem repeat (STR) allele frequency distributions in a Balinese population. Hum Mol Genet 1995;4:85-91.

6 Friedman, TB, Liang Y, Weber JL, et al. A gene responsible for congenital, recessive deafness DFNB 3 maps to the pericentromeric region of chromosome 17. Nature Genet 1995;9:86-91.

7 Hastbacka J, de la Chapelle A, Kaitila I, et al. Linkage disequilibrium mapping in isolated founder populations: diastrophic dysplasia in Finland. Nature Genet 1992;2: 204-11.
8 Luria SE, Delbruck M. Mutations of bacteria from virus sensitivity to virus resistance. Genetics 1943;28:491-511.

9 Asher JH Jr, Liang Y, Winata S, et al. Allele frequency dependent homozygosity mapping: an alternative strategy roc mapping diseases caused by fully

10 McKusick VA. Mendelian inheritance in man. 10th ed. Baltimore: Johns Hopkins University Press, 1992.

11 Warkany J. Congenital malformations: notes and comments. Chicago: Year Book Medical Publishers, 1971.

12 Jones LK. Smith's recognizable patterns of human malformation. Philadelphia: W B Saunders, 1988:709.

13 Buyse ML, ed. Birth defects encyclopedia. Dover, Mass: Center for Birth Defects Information Services Inc, 1990

14 Stevenson RE, Hall JG, Goodman RM, eds. Human malformations and related anomalies. Vol 1 and 2. New York: Oxford University Press, 1993.

15 Asher $\mathrm{JH} \mathrm{Jr}$, Morell R, Friedman TB. Waardenburg syndrome (WS): the analysis of a single family with a WS mutation showing linkage to RFLP markers on human chromosome 2q. Am f Hum Genet 1991;48:43-52.

16 Weber JL, Wong C. Mutation of human short tandem repeats. Hum Mol Genet 1993;2:1123-8.

17 Emery AEH. Methodology in medical genetics. In: $A n$ introduction to statistical methods. London: Churchill Livingston, 1986:37-54.

18 Chevillard C, LePaslier D, Passage E, et al. Relationship between Charcot-Marie-Tooth $1 \mathrm{~A}$ and Smith-Magenis regions. snU3 may be a candidate gene for the SmithMagenis syndrome. Hum Mol Genet 1993;2:1235-43.

19 NIH/CEPH Collaborative Mapping Group. A Comprehensive genetic linkage map of the human genome. Science 1992;258:67-87.

20 Fraser GR. Studies on isolates. F Genet Hum 1964;13:32-46.

21 Brownstein Z, Friedlander Y, Peritz E, Cohen T. Estimated number of loci for autosomal recessive severe nerve deafness within the Israeli Jewish population, with implications for genetic counseling. Am f Med Genet 1991;41:306-12.

22 for genetic counseling. Am f Med Genet 1991;41:306-12. North Am 1981;28:973-80.

23 Nance WE, McConnell FE. Status and prospects of research in hereditary deafness. In: Harris $\mathrm{H}$, Hirschhorn $\mathrm{K}$, eds. Advances in human genetics. New York: Academic Press, 1973:175-250.

24 Nance WE, Sweeney A. Genetic factors in deafness of early life. Otolaryngol Clin North Am 1975;8:19-48.

25 Marres HAM, Cremers WRJ. Autosomal recessive nonsyndromal profound childhood deafness in a large pedigree. Arch Otolaryngol Head Neck Surg 1989;115:591-5.

26 Guilford P, Ben Arab S, Blanchard S, et al. A non-syndromic form of neurosensory, recessive deafness maps to the pericentromeric region of chromosome 13q. Nature Genet 1994;6:24-8.

27 Guilford P, Ayadi H, Blanchard S, et al. A human gene responsible for neurosensory, nonsyndromic recessive deafness is a candidate homolog of the mouse $s h-1$ gene. Hum Mol Genet 1994;3:989-93. 